\title{
CAPABILITY PROCESS ASSESSMENT IN SIX SIGMA APPROACH
}

\section{INTRODUCTION}

We can state that statistical methods belong to a quality tools canon and a formal requirement of their application is contained in each contemporary quality management system, i.e. both in ISO 9000 standard group and in branch standards coming from ISO standards.

Statistical techniques occupy a particular place in the organizational culture Six Sigma that is used in many renowned organizations (Motorola, General Electric, Bombardier, Nokia, Sony, BMW, Philips etc.) in order to achieve in the shortest possible time the highest quality level. Six Sigma is, in other words, an efficient and verified program of organization profitability improvement; statistical methods play in this program a role of the basic and most important tool for better and better understanding and improving processes.

\section{CHARACTERISTIC FEATURES OF SIX SIGMA}

Among lots of definitions of Six Sigma there is one that is first worth mentioning - the one presented by Breyfogle [1] that says "Six Sigma is a strictly planned process leading to higher and higher quality in time shorter than at competitors". But Pande [2] defines Six Sigma as "A comprehensive and flexible system for achieving, sustaining, maximizing business success. Six Sigma is uniquely driven by a close understanding of customer needs, disciplined use of facts, data, and statistical analysis and diligent attention to managing, improving, and reinventing business processes". Indeed, all existing definitions of Six Sig-

* Ph.D.: Faculty of Metals Engineering and Industrial Computer Science, AGH University of Science and Technology, Cracow, Poland; czarski@uci.agh.edu.pl 
ma are brought to a common denominator of a new definition of quality and very intensive application of statistical techniques to improve processes - not suddenly, but incrementally. The new definition of quality expresses the right to value: a customer expects the product with desirable functional features, however from the producer's point of view, the product must "earn" money - realization of those seemingly divergent objectives is possible through pursuit of achievement of so-called perfect quality.

The new definition of quality is one of three mentioned characteristic features of Six Sigma $[3,4,5,6]$.

The second characteristic feature of Six Sigma is the determined organization structure, of which the most important content is staff dedicated to Six Sigma objectives. There are first of all: champion, master black belts, black belts, green belts and members of teams executing improvement projects. The key persons are, first of all, black belts and green belts who manage the mentioned teams executing improvement projects and they are responsible for the realization of those projects.

The third characteristic feature of Six Sigma, possibly the most important one, is an algorithm of realization of improvement projects, consisting of five phases Define-Measure-Analyze-Improve-Control (DMAIC).

Realization of the algorithm DMAIC is the basic phase of the so-called breakthrough strategy; through the execution of projects according to the algorithm DMAIC not incremental improvement occurs, but it should be a sudden improvement. Realization of this algorithm requires application of lots of different quality instruments. One of the most important are statistical techniques.

\section{CAPABILITY PROCESS ESTIMATION}

Estimation of a process capability refers to a comparison of the process variability with the expected, tolerable variability defined with the aid of specification limits. The expression of this comparison is a series of different capability indices that are capability indices of first generation ( $\mathrm{Cp}, \mathrm{Cpk}, \mathrm{Pp}, \mathrm{Ppk})$, capabi-lity indices of second generation (Cpm), capability indices in case of non-normal distributions, capability indices for correlated data, capability indices in case of multidimensional analysis etc. [7, 8].

\section{SIX SIGMA CAPABILITY}

\subsection{Conception, interpretation}

In the Six Sigma approach, analogously to the analysis of variance (ANOVA), the analysis of process variability is being performed considering sources that can be its reasons

$[1,9]$. The principle of this approach is as follows. The total process variability consists of 
the variability independent on time that we observe in successive rational subgroups taken from a process and the variability dependent on time observed from a sample to a sample. Relating client's expectations presented as specification limits to the total process variability is expressed in long-term capability indices Pp, Ppk. Relating client's expectations presented as specification limits to a component of the process variability irrespective of time is expressed in short-term capability indices $\mathrm{Cp}, \mathrm{Cpk}$.

In order to interpret process capability indices $\mathrm{Cp}, \mathrm{Cpk}$ (the same interpretation concerns also indices Pp, Ppk) let's use the following analogy. In a production process a specified product is manufactured, in a measurement process we "produce" numbers. A good measurement should be correct and precise. From the point of view of correctness, a good measurement means the measurement without a systematic error. Precision is connected with a dispersion of measurement results round an unknown value of the measured parameter. At more precise measurement the dispersion of measurement results is the smallest. Because, regarding the variability, a measurement and production process can be treated the same, we can say also that a good process should be - a good measurement similarly correct and precise, too. The relative measure of a process correctness is the real capability factor $\mathrm{Cpk}$; if $\mathrm{Cpk}=\mathrm{Cp}$, the process is centered that means the expected realization of the process corresponds to the target (the midpoint of a specification limit). If $\mathrm{Cpk}<\mathrm{Cp}$, the position of the process is improper, the process is displaced.

The relative measure of a process precision is the potential capability factor $\mathrm{Cp}$; the higher value of this factor, the lesser variability of the process relating to the variability declared by specification limits.

Of course, there is an unequivocal relationship (for given distribution) between values of capability indices $\mathrm{Cp}, \mathrm{Cpk}$ and a fraction of the realization outside specification limits (limit).

\subsection{Calculation procedure}

The assessment of non-dependent time variability. We take rational subgroups of a specified size from the on-going process. For each sample we can determine one of the following dispersion measures: range $(R)$, standard deviation $(s)$ or variance $\left(s^{2}\right)$. The measure of the variability independent on time is a standard deviation $s_{\text {short }}$. For the assessment of $s_{\text {shert }}$ one can use: average range $(\bar{R})$ or average standard deviation $(\bar{s})$ or average

variance $\left(s^{2}\right)$. Obviously, the point is in averages determined on the basis of particular samples taken from the process.

The assessment of total variability. From all the samples taken from the on-going process we make one set. Variability observed in this set is a total variability. The measure of this variability is a standard deviation $s_{\text {long }}$ determined on the basis of this set.

Having at our disposal the measure of variability independent on time $s_{\text {short }}$ and the measure of total variability $s_{\text {long }}$ we can determine correspondingly short-term capability indices $\mathrm{Cp}$, Cpk and long-term capability indices Pp, Ppk. (Tab. 1). 
Table 1. List of short-term and long-term capability indices - calculation procedure $[1,9]$

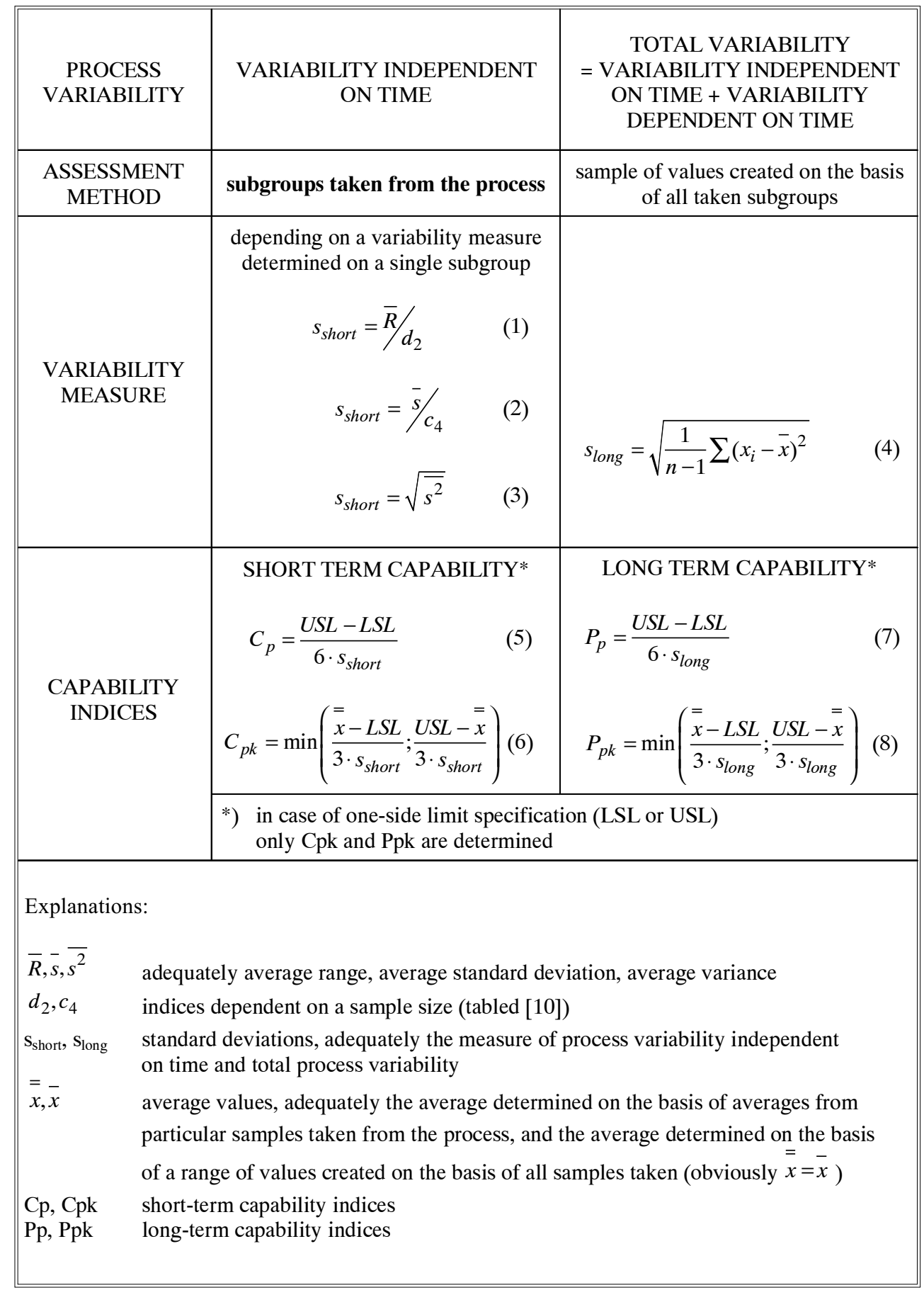




\subsection{Conclusions on the basis of analysis results}

- If standard deviations $s_{\text {short }}$ and $s_{\text {long }}$ are equal i.e. $s_{\text {short }}=s_{\text {long }}$, the total process variability consists only of variability independent on time. The independent-on-time variability is a so-called noise.

Equality $s_{\text {short }}=s_{\text {long }}$ involves the equality of adequate short-term and long-term capability indices i.e. $\mathrm{Cp}=\mathrm{Pp}$ and $\mathrm{Cpk}=\mathrm{Ppk}$.

Moreover, if the process is centered that means the average corresponds to a target (a midpoint of the specification area), there are the equalities: $\mathrm{Cpk}=\mathrm{Ppk}$ and $\mathrm{Cp}=\mathrm{Pp}$.

- If there is an inequality $s_{\text {short }}<s_{\text {long }}$, the total process variability is larger than the variability caused by the noise, so a position of the considered process was being changed crucially in time (e.g. because of periodical changes of raw materials, settings etc.).

The inequality $s_{\text {short }}<s_{\text {long }}$ involves the following relations between short-term and long-term capability indices: $\mathrm{Cp}>\mathrm{Pp}$ and $\mathrm{Cpk}>\mathrm{Ppk}$.

- We can demonstrate that there are the following relationships between short-term and long-term process capability indices [9]:

$\mathrm{Ppk}<\mathrm{Cpk}<\mathrm{Cp}$ and $\mathrm{Ppk}<\mathrm{Pp}<\mathrm{Cp}$

$\mathrm{Pp} \mathrm{Cpk}=\mathrm{Cp} \mathrm{Ppk}$

Expression (10) can be used for verification of the calculation correctness.

\section{EXPERIMENTAL PROCEDURE}

\subsection{Aim, material}

The aim of research is an assessment of short-term and long-term capability for the sake of hardness of drop forgings (steel 41Cr4, PN-EN 10083-1+Ap1:2003).

The process of quenching and tempering (hardening and high-temperature tempering) of drop forgings is carried out in a tunnel furnace with regulation of a temperature and atmosphere in particular zones. Forgings heated to the temperature of $850^{\circ} \mathrm{C}$ get to a quenching tank and than they are being tempered at the temperature $580-600^{\circ} \mathrm{C}$. The tempering time is regulated by a tape speed.

The material is delivered by batches. The batches are supplied for a heat treatment irregularly, that requires to set the process for each individual batch.

During the heat treatment of the batch every determined time five forgings are taken (the sample of five elements, $n=5$ ) and for each forging a hardness measurement is made. The Rockwell ZHR 4150 AK hardness tester of Zwick company is being used for measurements that is suitable to control the process with sufficient precision.

According to client's expectations the specification limits for hardness of drop forgings after quenching and tempering are as follows: lower specification limit DWG $=30 \mathrm{HRC}$, upper specification limit GWG $=40 \mathrm{HRC}$. 


\subsection{Experimental results}

The analysis of the process capability is made for six batches of drop forgings. The results of measurements are presented in Table 2 and in Figure 1.

Table 2. Results of hardness measurements

\begin{tabular}{|c|c|c|c|c|c|c|c|c|}
\hline Batch & $\begin{array}{c}\text { No. of } \\
\text { subgroups }\end{array}$ & \multicolumn{5}{|c|}{ Values } & $\mathrm{R}$ & $\mathrm{x}$-bar \\
\hline \multirow{4}{*}{1} & 1 & 34 & 33 & 34 & 35 & 35 & 2 & 34,2 \\
\hline & 2 & 35 & 32 & 34 & 35 & 33 & 3 & 33,8 \\
\hline & 3 & 33 & 33 & 33 & 33 & 33 & 0 & 33,0 \\
\hline & 4 & 32 & 34 & 34 & 34 & 34 & 2 & 33,6 \\
\hline \multirow{6}{*}{2} & 5 & 37 & 36 & 37 & 36 & 35 & 2 & 36,2 \\
\hline & 6 & 36 & 37 & 37 & 37 & 36 & 1 & 36,6 \\
\hline & 7 & 35 & 38 & 37 & 36 & 37 & 3 & 36,6 \\
\hline & 8 & 35 & 38 & 35 & 36 & 39 & 4 & 36,6 \\
\hline & 9 & 36 & 37 & 34 & 36 & 37 & 3 & 36,0 \\
\hline & 10 & 38 & 38 & 36 & 36 & 36 & 2 & 36,8 \\
\hline \multirow{3}{*}{3} & 11 & 35 & 35 & 36 & 34 & 37 & 3 & 35,4 \\
\hline & 12 & 36 & 34 & 35 & 35 & 35 & 2 & 35,0 \\
\hline & 13 & 35 & 35 & 34 & 35 & 36 & 2 & 35,0 \\
\hline \multirow{4}{*}{4} & 14 & 33 & 35 & 33 & 34 & 35 & 2 & 34,0 \\
\hline & 15 & 35 & 34 & 34 & 34 & 35 & 1 & 34,4 \\
\hline & 16 & 34 & 33 & 34 & 33 & 34 & 1 & 33,6 \\
\hline & 17 & 35 & 34 & 33 & 35 & 34 & 2 & 34,2 \\
\hline \multirow{5}{*}{5} & 18 & 35 & 37 & 36 & 37 & 37 & 2 & 36,4 \\
\hline & 19 & 35 & 35 & 37 & 36 & 36 & 2 & 35,8 \\
\hline & 20 & 37 & 37 & 36 & 36 & 36 & 1 & 36,4 \\
\hline & 21 & 35 & 36 & 37 & 36 & 36 & 2 & 36,0 \\
\hline & 22 & 37 & 34 & 36 & 34 & 35 & 3 & 35,2 \\
\hline \multirow{3}{*}{6} & 23 & 34 & 34 & 34 & 36 & 36 & 2 & 34,8 \\
\hline & 24 & 34 & 35 & 34 & 34 & 34 & 1 & 34,2 \\
\hline & 25 & 35 & 33 & 33 & 35 & 35 & 2 & 34,2 \\
\hline
\end{tabular}



Fig. 1. Results of hardness measurements 
On the basis of the results achieved the short-term capability indices $\mathrm{Cp}$, Cpk and longterm capability indices Pp, Ppk (Tab. 3) have been determined.

Table 3. List of results of process capability assessment

\begin{tabular}{||l|l|l|l||}
\hline \hline LSL; USL & $30 ; 40$ & $\mathrm{Cp}$ & 1,94 \\
\hline $\bar{R}$ & 2 & $\mathrm{Cpk}$ & 1,89 \\
\hline $\mathrm{S}_{\text {short }}{ }^{*}$ & 0,86 & $\mathrm{Pp}$ & 1,17 \\
\hline $\mathrm{S}_{\text {long }}$ & 1,42 & $\mathrm{Ppk}$ & 1,14 \\
\hline$*$ in case of the sample $\mathrm{n}=5 \mathrm{~d}_{2}=2.326[10]$ \\
\hline
\end{tabular}

\subsection{Discussion of results}

The considered process used to change the position in time. Therefore, there is a component of the variability dependent on time; hence the total process variability, of which the measure is a standard deviation $s_{\text {long }}$, is larger than the variability independent on time generated only by a component independent on time, of which the measure is a standard deviation $s_{\text {short }}($ Tab. 3). In consequence $\mathrm{Pp}<\mathrm{Cp}$ and $\mathrm{Ppk}<\mathrm{Cpk}$ (Tab. 3); because there is a component of the variability dependent on time, the process potential regarding the expectations declared through the specification limits becomes worse.

A component of the process variability independent on time relating to client's expectations (expressed by indices $\mathrm{Cp}$, Cpk) first of all determines technical and technological potential of the heat treatment process (regulation of the temperature, distributions of the temperature in particular zones, properties of the quenchant, process control by operators etc.). The presence of the component of variability dependent on time (from batch to batch) can speak for difficulties within the process setting in case of next batches, and also for diversification of next batches as for the material.

\section{SUMMARY}

Statistics is the only way to describe a performance of any process in variability conditions. Let's say more - statistics is an art of analyzing variability sources i.e. making analysis in which the variability can be divided into components coming from separated sources. Treating the matter more generally and more formally one can use an expression that statistics is one big analysis of variance (ANOVA).

The separating of variability sources mentioned above is the basis of determination of short-term and long-term process capability, where we decompose the total process variability for two components: the component independent on time and the component dependent on time. No doubt that such a partition of the variability is necessary, it enables the better understanding of the process and in consequence - its improvement.

Such a separation of the variability in some matters - let's determine it generally of quality management is nothing new. The similar situation we can meet in case of the 
assessment of repeatability and reproducibility of a measurement system (e.g. using R\&R method). In the R\&R analysis from the total variability accompanying a measurement we separate a component for which a measurement device is responsible (it is a so-called reproducibility) as well as a component for which operators are responsible (it is a so-called repeatability). Such a distinction of the variability is also necessary because it brings some determined information that can be managed.

\section{Acknowledgements}

The financial support from the Polish Ministry of Science and Higher Education, contract AGH no.10.10.110.797 is gratefully acknowledged.

\section{REFERENCES}

[1] Breyfogle F.W.: III, Implementing Six Sigma. Smarter Solutions Using Statistical Methods, Second Edition, John Wiley\&Sons, Inc., 2003

[2] Pande P.S., Neuman R.P., Cavanagh R.R.: Six Sigma. How GE, Motorola and Other Top Companies are Honning Their Performance, KE Liber S.C., 2000 (in Polish)

[3] Pande P., Holpp L.: What is Six Sigma, First Edition, McGraw-Hill, 2001

[4] Stamatis D.H.: Six Sigma and Beyond. Foundations of Excellent Performance. Ed. CRC Press, 2001

[5] Rath\&Strong's Six Sigma leadership handbook, Edited by Thomas Bertels, John Wiley\&Sons, Inc., 2003

[6] Six Sigma. International Conference, Wroclaw Centre for Technology Transfer, Wroclaw University of Technology, January 2004 (in Polish)

[7] Montgomery D.C.: Introduction to Statistical Quality Control, Third Edition, John Wiley\&Sons, Inc., 1997

[8] Kotz S., Lovelace C.R.: Proces Capability Indices in Theory and Practice, Arnold, 1998

[9] Joglekar A.M.: Statistical Methods for Six Sigma. In R\&D and Manufacturing, John Wiley\&Sons, Inc., 2003

[10] Glossary and Tables for Statistical Quality Control, Third Edition, ASQ Statistics Division, ASQ Quality Press, 1996

Received

September 2007 